Samuel Vollenweider

\title{
Hymnus, Enkomion oder Psalm? Schattengefechte in der neutestamentlichen Wissenschaft
}

\begin{abstract}
Hymnus"
For much of the $20^{\text {th }}$ century scholars tried to reconstruct various cultic hymns beneath the surface of New Testament texts. With the rise of rhetorical criticism the focus of research has shifted to the properties of epideictic rhetoric. Exegetes, therefore, often tend to contrast "encomia" with "hymns" or "psalms". To avoid any shadow boxing one has to consider which descriptive language would fit best the texts. A brief examination of ancient hymnic traditions and their treatment in rhetoric demonstrates that while encomia interact strongly with hymns each genre has its own characteristics; hymns, whether in poetry or prose, consist especially of praise of divinities and are addressed to divinities. Future formgeschichtliche analysis has to distinguish carefully between "hymn" (in a narrow sense), "hymnic praise" and "encomion" (which does not refer particularly to divine beings). In early Christian literature, as far as it relates to the textual surface, we find beside hymns to God only few hymns directed to Christ. Nevertheless Christ's divine status is praised with rich hymnic rhetorical devices. This amazing tension corresponds exactly with what we call "Christological monotheism".
\end{abstract}

Keywords: Hymn, Psalm, Encomium, Rhetoric, Formgeschichte, Prayer, Cult, Christology, Monotheism

\section{Zwischen Formgeschichte und Rhetorik}

„Verstanden werden kann dieses Kyrios-Bekenntnis <sc. Phil 2,6-11> nur von der frommen Einfalt stillster Andacht. Man lasse alle Kommentare beiseite und bitte einen anatolischen Christen, den Urtext dieses Bekenntnisses einmal leise vorzulesen, in dem psalmodierenden Rhythmus, in dem der christliche Osten die Perikopen der griechischen Bibel im Halbdunkel seiner Kirchen liest: ein Teil der Untertöne des alten Psalms wird dann wieder lebendig, wir werden frei vom Elend der Historie, und wir kommen in einen kultischen Kontakt mit den armen Heiligen Macedoniens, die die ersten Eigentümer des Schatzes waren.“ 
In geradezu beschwörendem Ton stellt uns Adolf Deissmann in seinem Paulusbuch das Gewicht urchristlicher Kulttexte vor Augen. ${ }^{1}$ Die Bibelwissenschaften des 20 . Jahrhunderts haben mit viel Elan hinter den biblischen Texten Überlieferungsstuicke identifiziert, die sich als unmittelbarer Niederschlag kultischer Praxis verstehen und so einem bestimmten ,Sitz im Leben“ zuweisen liessen. Das Interesse der Formgeschichte, die mit der Orientierung der Religionsgeschichtlichen Schule am urchristlichen Kult einherging, richtete sich auf die Bestimmung von Kriterien, die die Rekonstruktion älterer kleiner Formen gottesdienstlicher Herkunft ermöglichen sollten: gehobener Stil, strophische Gliederung, sprachlicher Rhythmus, Relativ- und Partizipialstil, aber auch Kontextüberschuss und theologisches Sondergut. Angeregt von der alttestamentlichen Wissenschaft, die den kultischen Hintergrund des Psalters und seiner Gattungen entdeckte, hat sich auch die neutestamentliche Exegese nicht davon abhalten lassen, ihren ungleich sperrigeren und widerständigeren Texten authentische Dokumente des gottesdienstlichen Lebens zu entlocken. ${ }^{2}$ Bei allem Bewusstsein um den hypothetischen Charakter dieses Zugriffs fand man in der frühchristlichen Literatur eine stattliche Reihe von zumeist fragmentarischen Liedern und Hymnen, deren Auflistung schliesslich zum festen Bestand von Lehrbuch und Proseminar-Manual gehören sollte. ${ }^{3}$ Bereits beim Philologen Josef Kroll nehmen sich die wenigen erhaltenen oder rekonstruierten Fragmente christlicher Hymnodik wie verstreute Inseln einer versunkenen gewaltigen

1 A. Deissmann, Paulus, Tübingen ${ }^{2}$ 1925, 150. Deissmann selber schreibt einem Text wie Phil 2,6-11 freilich paulinische Verfasserschaft zu. Scharfe Kritik am „Christuskult“ übte D.E. v.DoBschÜTZ, Aus der Umwelt des Neuen Testaments, ThStKr 95 (1923/24) 314-332: 328330 (,das Urchristentum ist im höchsten Grade unkultisch“) (freundlicher Hinweis von K. Haacker).

2 Dabei fällt auf, dass die Detailarbeit erst ab den 1960er Jahren geleistet wird. Vgl. G. SCHILLE, Frühchristliche Hymnen, Berlin 1965; J. SchatTENMANN, Studien zum neutestamentlichen Prosahymnus, München 1965; R. DEICHGRÄBER, Gotteshymnus und Christushymnus in der frühen Christenheit, 1967 (StUNT 5); R.P. MARTIN, Carmen Christi. Philippians ii.5-11 in recent Interpretation and in the Setting of early Christian Worship, 1967 (21983) (MSSNTS 4); ders., New Testament Hymns, ExpT 94 (1982/83) 132-136; K. WENGST, Christologische Formeln und Lieder des Urchristentums, ${ }^{2} 1973$ (StNT 7); J.T. SANDERS, The New Testament Christological Hymns, 1971 (MSSNTS 15); Ph. VIELHAUER, Geschichte der urchristlichen Literatur, Berlin 1978, 40-49; Nachzügler: G. KENNEL, Frühchristliche Hymnen? Gattungskritische Studien zur Frage nach den Liedern der frühen Christenheit, , 1995 (WMANT 71). Im Rückblick zeigt sich: Zählt man am Anfang enorm viele Hymnen (Schille kommt auf rund 30 neutestamentliche Texte), reduziert sich deren Zahl mit der Zeit erheblich (Kennel beschränkt sich exemplarisch noch auf zwei).

3 Vgl. exemplarisch H. Conzelmann/ A. Lindemann, Arbeitsbuch zum Neuen Testament, ${ }^{14} 2004$ (UTB 52), 136-142. 
urchristlichen Hymnendichtung aus, die von der Alten Kirche erfolgreich verdrängt worden ist. ${ }^{4}$ Martin Hengel hat schliesslich das inspirierende Bild des Urchristentums als geistgetriebener Kultgemeinde, die eine neue messianische Psalmendichtung erschuf, plastisch vor Augen gestellt. ${ }^{5}$

Die erheblichen methodischen Schwierigkeiten dieses klassischen formgeschichtlichen Unternehmens sind offenkundig. ${ }^{6}$ Das Misstrauen gegenüber dem direkten Rückschluss von den Texten auf kultische und liturgische Handlungen hat sich etwa auch im Blick auf Gebetstexte oder auf die Abendmahlsüberlieferungen verstärkt. ${ }^{7}$ Im Bereich der Hymnen weckt allein schon die enorme Divergenz der verschiedenen Rekonstruktionsvorschläge Unbehagen. Erschwerend kommt hinzu, dass man meist Interpolationen der älteren Stücke durch die neutestamentlichen Autoren behaupten muss, während man umgekehrt die Möglichkeit, dass Zeilen ausgelassen wurden, ausblendet. Das Argument von Spannungen auf der theologischen Ebene, die eine Unterscheidung von überkommener Überlieferung und vorfindlichem Text nahelegen, ist tendenziell der Gefahr von Überbelichtung ausgesetzt. Die Wahrnehmung mangelnder gedanklicher Kohärenz und Inkonsistenz entspringt oft eher dem Herantragen neuzeitlicher Kategorien an die antiken Texte, als dass sie deren Dekonstruktion erlauben könnte. Schliesslich ist auch das ausschlaggebende Argument, das auf der sprachlichen Ebene spielt, in Schieflage geraten. Die jüngere Wiederentdeckung der antik-rhetorischen Kategorien durch die Exegese rückt die Interpretation der zu erklärenden Phänomene in ein anderes Licht. Stilistische Beobachtungen sind als solche kein hinreichender Grund, diachrone Überlieferungsprozesse zu postulieren; möglicherweise lassen sie sich methodisch anspruchsloser lediglich als Indizien für einen Stilwechsel auf der Ebene des vorliegenden Texts deuten. Auch

4 J. KROLL, Die christliche Hymnodik bis zu Klemens von Alexandreia. Nachdruck der Ausgabe von 1921/22, ${ }^{2} 1968$ (Libelli 140), mit dem Verweis auf die ungezügelte Hypothesenfreudigkeit im 19. Jh. (,Was hat man nicht alles von ,Bruchstücken aus Kirchenliedern’ z.B. bei Paulus gefabelt", 12 A.1).

5 M. Hengel, Das Christuslied im frühesten Gottesdienst (1987), in: ders., Studien zur Christologie. Kleine Schriften IV, 2006 (WUNT 201), 205-258; vgl. auch M. DALY-DENTON, Singing Hymns to Christ as to a God, in: C.C. NewMAN u.a. (Hg.), The Jewish Roots of Christological Monotheism, 1999 (JSJ.S 63), 277-292.

6 Vgl. insbesondere die exzellente Arbeit von R. BRUCKER, ,Christushymnen' oder, epideiktische Passagen'? Studien zum Stilwechsel im Neuen Testament und seiner Umwelt, 1997 (FRLANT 176); ferner M. PEPPARD, ,Poetry', ,Hymns' and ,traditional Material' in New Testament Epistles or How to do things with indentations, JSNT 30 (2008) 319-342; J.-N. ALETTI, Les passages néotestamentaires en prose rythmée, in: D. GERBER/ P. KEITH (Hg.), Les hymnes du Nouveau Testament et leurs fonctions, Paris 2009, 239-263.

7 Vgl. H. LÖHR, Studien zum frühchristlichen und frühjüdischen Gebet, 2003 (WUNT 160), 63 66; 365f; 513f; J. SCHRÖTER, Die Funktion der Herrenmahlsüberlieferungen im 1. Korintherbrief, ZNW 100 (2009) 78-100. 
bei anderen Auffälligkeiten wie Sondervokabular und über den unmittelbaren Kontext hinausgreifenden Vorstellungselementen ist zu prüfen, ob man mit dem Verweis auf die Änderung des Stilmodus nicht auskommt.

Ohne das Recht der Rückfrage nach möglichen vorliterarischen Formen und nach kultischen Hintergründen grundsätzlich aufgeben zu müssen, ist man methodisch besser beraten, zunächst auf der Ebene der vorfindlichen Texte literarische Form und argumentative bzw. narrative Funktion zu bestimmen. ${ }^{8}$ So kristallisiert sich eine spezifische Fragestellung heraus: Gibt ein Text Hinweise, die seine Beschreibung mit der Kategorie des „Hymnus“ nahelegen? Wir haben uns damit der Frage zu stellen, was wir mit „Hymnus“ bezeichnen wollen.

\section{Was ist ein "Hymnus"?}

Parallel zum wachsenden Misstrauen gegenüber einem Rückschluss auf festes liturgisches Überlieferungsgut hat sich die Verunsicherung in Bezug auf die Gattungsbestimmung verstärkt. Anstelle des „Hymnus“, bei dem die kultische Funktion im Vordergrund steht, bemüht man heute gern das „Enkomion“, also eine Klassifikation aus dem Bereich der rhetorischen Theorie..$^{9}$ Auf der anderen Seite bevorzugt man aus religionsgeschichtlichen Gründen gegenüber dem als zu griechisch empfundenen Hymnus den „Psalm“ als angemessene Kategorie. ${ }^{10}$ Offenkundig ist es die unklare Bestimmung der Beschreibungssprache, die zur Aufrichtung von verwirrenden und möglicherweise falschen Alternativen führt - und damit $\mathrm{zu}$ wenig ergiebigen exegetischen Schattengefechten.

Im Folgenden formuliere ich einige Leitplanken für einen den Texten angemessenen Umgang mit der Kategorie des „Hymnus“. Eine Begriffsbestimmung des von Haus aus griechischen Terminus muss m.E. wenigstens drei Bedingungen erfüllen: (1.) Sie hat die grosse

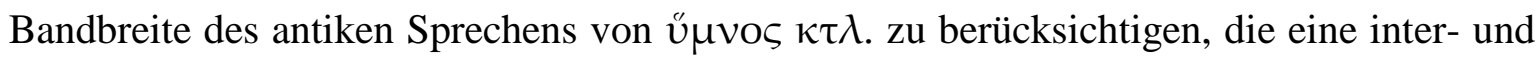
transkulturelle Polyvalenz dokumentiert. (2.) Sie hat sich an den spezifischen Eigentümlichkeiten des griechischen Hymnus zu orientieren. (3.) Sie hat sich zugleich abzustimmen auf den in Religionswissenschaft, Theologie und Altertumswissenschaften eingebürgerten Terminus, der sich seinerseits der markanten interkulturellen Anschlussfähigkeit des griechischen Begriffs verdankt. Während es sich beim ersten Eckpunkt um eine objektsprachliche Angelegenheit handelt, bewegen wir uns mit dem zweiten und dritten Punkt weitgehend auf einer beschreibungssprachlichen Ebene.

8 So konsequent der jüngste Sammelband: GeRBER/ KeITH, Hymnes (s. Anm. 6).

9 So besonders K. BERGER, Formgeschichte des Neuen Testaments, Heidelberg 1984, 344-346; vgl. 239-242; ders., Hellenistische Gattungen im Neuen Testament, 1984 (ANRW II/25/2), 1031-1432: 1173-1194.

10 So Hengel, Christuslied (s. Anm. 5) 247; 253. 


\subsection{Antike Terminologie und Klassifizierungen}

1. Die Semantik des griechischen Lexems $v$ $\mu \nu \circ \varsigma \kappa \tau \lambda$. ist breit und überaus unscharf. ${ }^{11}$ Immerhin verdichtet sie sich früh in der Bedeutung „Lied für einen Gott“, „Gesang, der Götter als Inhalt und Gegenüber hat". Bereits Platon unterscheidet den Hymnus, der Götter adressiert, vom Enkomion, dem Preislied auf einen Menschen. ${ }^{12}$ Die rhetorische Theorie bleibt an diesem Punkt über die Jahrhunderte hinweg eindeutig und stabil: ${ }^{13}$ Epideiktisches Reden, also das Lob, wird im Hinblick auf das Objekt differenziert; gilt das Lob den Göttern,

11 Vgl. die umfassenden Darstellungen R. WÜNSCH, Art. Hymnos, PWK 9/1 (1914) 140-183; M. LATTKE, Hymnus. Materialien zu einer Geschichte der antiken Hymnologie (NTOA 19), 1991, 1-10; K. THRAEDE, Art. Hymnus (1), RAC 16 (1994) 915-946; W. BURKERT, Griechische Hymnoi, in: W. BURKERT/ F. STOLZ (Hg.), Hymnen der Alten Welt im Kulturvergleich (OBO 131), 1994, 9-17; W.D. FURLEY/ J.M. BREMER (Hg.), Greek Hymns, I, 2001 (STAC 9), 1-64.

12 Platon, rep 10: 607a: ,doch sollst du wissen, dass wir von der Dichtung nur Götterhymnen und

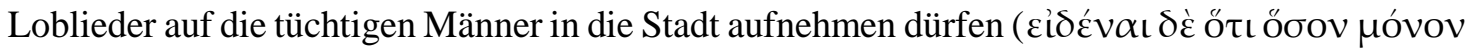

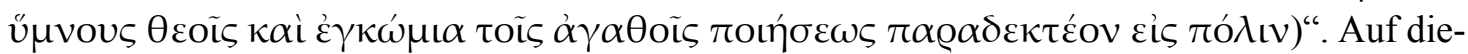
ser Linie lässt sich leg 7: 801e wie folgt übersetzen (vgl. S. PULLEYN, Prayer in Greek Religion, 1997 [Oxford Classical Monographs], 46 A. 19): „es wäre nun gewiss am richtigsten, für die Götter Hymnen, also Loblieder verbunden mit Gebeten, anzustimmen, und nach den Göttern müssten es dann die Daimonen und die Heroen sein, denen man mit Lobliedern verbundene

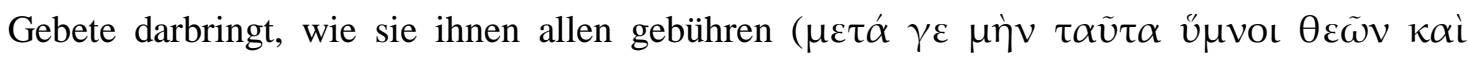

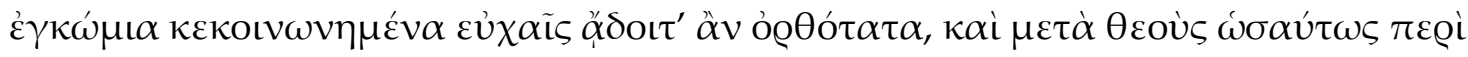

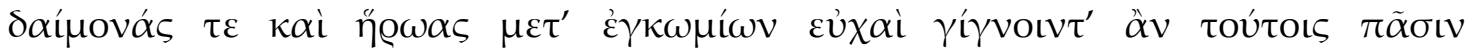
$\pi \varrho \varepsilon ́ \pi \sigma v \sigma \alpha \mathrm{\iota})$ “. Allerdings unterscheidet Platon anderwärts nicht scharf zwischen Hymnen, Enkomien und Gebeten.

13 Dabei rangiert der Hymnus entweder als Spezialfall des Oberbegriffs Enkomion/Epainos oder

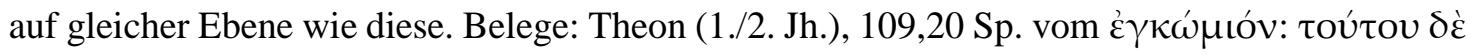

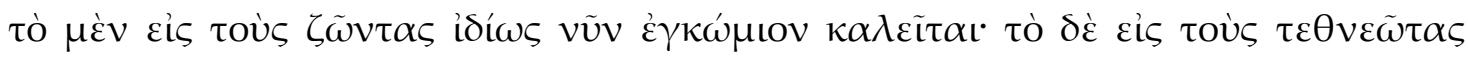

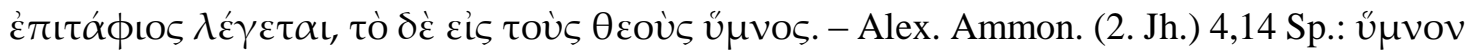

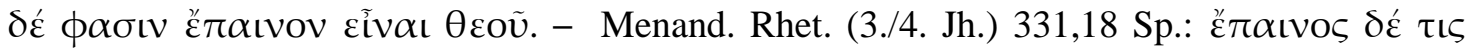

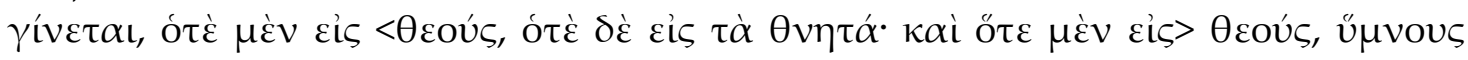

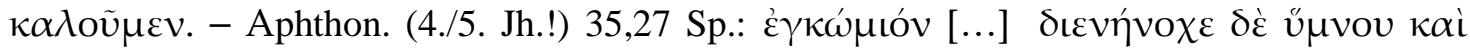

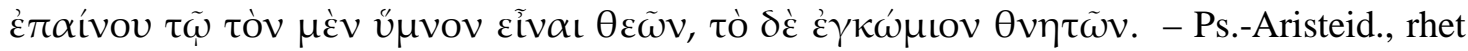

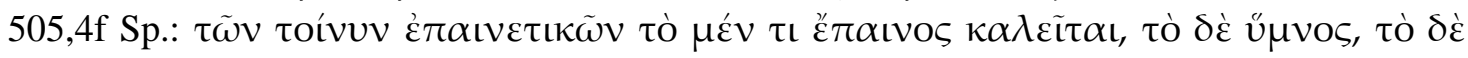

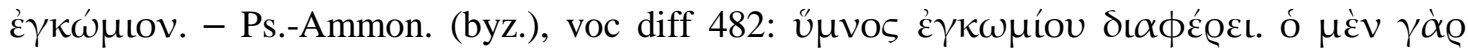

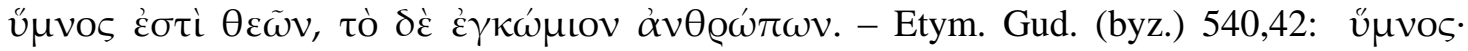

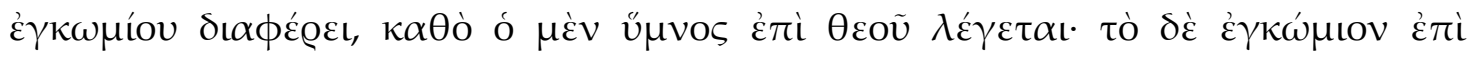
$\alpha v \theta \varrho \omega \pi$ ov. - Die Bindung des Hymnus an Gott belegt auch die Definition Augustins, enarr Ps 148,17 (CCL 40, 2177): hymnus ergo tria ista habet, et cantum, et laudem, et dei. laus ergo dei in cantico, hymnus dicitur (zum hier genannten Kriterium des Gesangs vgl. unten Anm. 55). Die Adressierung an eine Gottheit hat zur Folge, dass das Element der Gebetshaltung den Hymnus charakteristisch vom Enkomion unterscheidet: Vgl. ScholLond Dion. Thrax p. 451,6 H.:

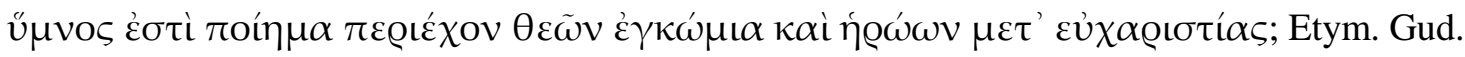

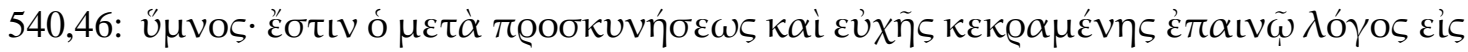
$\theta \varepsilon o ́ v$ („Hymnus: eine Rede an einen Gott in Gestalt von Anbetung, verbunden mit Bitte und Lob"). 
handelt es sich um einen Hymnus; die übrigen Arten des Lobs richten sich auf Sterbliches. ${ }^{14}$ Allein schon diese kleine Beobachtung signalisiert, dass die in der Exegese beliebte Kontrastierung von Hymnus und Enkomion der antik-rhetorischen Sprachregelung zuwiderläuft.

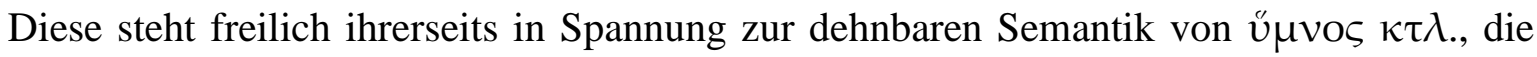
weit über göttliche Wesen hinausgreift. Ausserdem ist bei der genannten Differenzierung zu beachten, dass die Grenzen zwischen Göttern und Menschen flexibel sind; so gelten Hymnen nicht nur Göttern, sondern auch Heroen und deifizierten Menschen, zumal Herrschern.

Bevor wir zur rhetorischen Theorie zurückkehren, ist an die interkulturelle Anschlussfähigkeit des griechischen Wortfelds zu erinnern. Bekanntlich hat das griechischsprachige Judentum seine Psalmen auch als „Hymnen“ bezeichnet und damit in den Zusammenhang des griechisch-hellenistischen Lobs göttlicher Wesen gestellt. ${ }^{15}$ Dies geschieht gelegentlich in der Septuaginta, häufig bei Josephus und exklusiv bei Philon. ${ }^{16}$

2. Die Rhetoriktheorie bietet relativ wenig Material zum Hymnus, da er von Haus aus kein Redegenus darstellt. Die einzige substanzielle Abhandlung bietet Menander Rhetor, etwa um 300 n.Chr., im Rahmen seiner Darstellung der epideiktischen Rhetorik. ${ }^{17}$

Diese gliedert sich in Lob und Tadel. Bezieht sich das Lob auf Götter, handelt es sich um Hymnen (331,15-20 Sp.). Es folgt eine Glosse, die die je nach Gottheit

14 Menand. Rhet. aaO. teilt weiter in Städte (samt Ländern) sowie Lebewesen. Die Letzteren schliessen Vernünftiges, also Menschen, und Unvernünftiges zusammen. Dieses gliedert sich seinerseits in Festlandwesen und Wasserwesen, die Ersteren wiederum in Geflügelte und Fusswesen. Eine Glosse schliesst auch Blumen und Pflanzen ein $(332,18)$.

15 Die griechischen Pseudepigraphen verweisen gern auf den Hymnengesang, insbesondere in Bezug auf die Engel. Den Zusammenhang von Hymnen und Psalmen zeigt das Syntagma ǔ $\mu$ vous

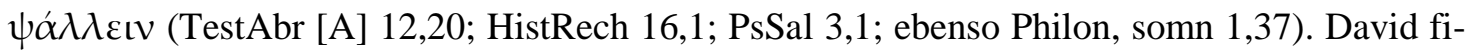

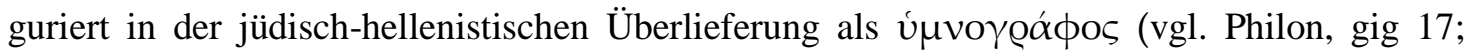

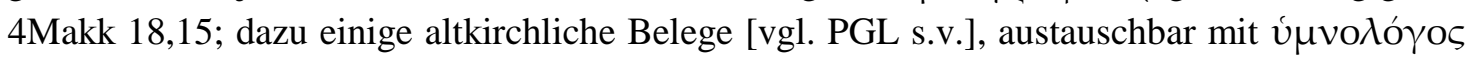

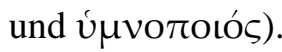

16 Vgl. die Übersicht bei G. Delling, Art. úpvos, ThWNT 8 (1969) 492-506: 499f. - Josephus rückt „Hymnen“ und „Psalmen“ nahe zusammen (ant 6,166-168.214; 7,80; 9,269; 12,323.349; vgl. TestHiob 14,2).

17 Das Euvre unter Menanders Namen besteht aus zwei Lehrbüchern wohl verschiedener Verfasser. Vgl. D.A. RusSELl/ N.G. WILSON (Hg.), Menander Rhetor, Oxford 1981, xxxviii; ferner E. KRENTZ, Epideiktik and Hymnody. The New Testament and its World, BR 40 (1995) 50-97: 62-71; F. GASCÓ, Menander Rhetor and the Works attributed to him, ANRW II 34/4 (1998) 3110-3146: 3113-3115; A.-M. FAVREAU-LINDER, L'hymne et son public dans les traités rhétoriques de Ménandros de Laodicée, in: Y. LEHMANN (Hg.), L'hymne antique et son public, Turnhout 2007, 153-167. Zu den epideiktischen Traktaten findet sich fast gar nichts bei M. HEATH, Menander. A Rhetor in Context, Oxford 2004, 93-213. 
unterschiedenen Gattungen von Hymnen differenziert. ${ }^{18}$ Interessanter ist Menanders Vollständigkeit beanspruchende Klassifizierung von acht Typen, der eine unsystematische Koordination von funktionalen und inhaltlichen Kriterien zugrunde liegt. ${ }^{19}$

Wir halten für unsere Fragestellung drei Beobachtungen fest: (1.) Bei rund der Hälfte der Klassen besteht eine grosse Nähe zum Gebet. Dazu passt es, dass beim hymnos physikos, der den Typ des philosophischen Hymnus repräsentiert, das Fehlen des Bittgebets eigens festgehalten wird $(337,25 f)$. (2.) Der philosophische Hymnus, der auf dem höchsten Stilniveau spielt, nimmt eine prominente Position ein (336,24-337,32). (3.) Das Vorhandensein zahlreicher Mischformen wird konstatiert $(343,27-344,4)$.

\subsection{Griechische Hymnen}

Im Bereich griechischer Hymnen ist ein weites Feld in den Blick zu nehmen, in formaler, inhaltlicher wie zeitlicher Hinsicht. Ich orientiere mich für meinen Überblick an vier Wegmarken: Sprachgestalt, Struktur, Funktion und Reflexion. Das Augenmerk gilt spezifischen Eigenarten des griechischen Hymnus; Generelles stellen wir vorderhand zurück.

1. Für griechisches Empfinden ist der Hymnus recht zäh an das Metrum gebunden, stellt also Dichtung dar. Dies geht so weit, dass Josephus der hebräischen Poesie, ihren „Oden an Gott und Hymnen“, klassische Metren zuschreibt. Philon seinerseits setzt deren Kenntnis auch bei Mose und vor allem bei den Therapeuten voraus. ${ }^{20}$ Hymnen orientalischer Herkunft kleiden sich wie im Fall der Isis gelegentlich in antike Verse; ${ }^{21}$ auch Zauberhymnen mühen sich um metrische Gestaltung. ${ }^{22}$ Demgegenüber sind für unsere Fragestellung nach „,neutestamentlichen Hymnen“ Prosahymnen von grossem Interesse. Sie stehen in starker Wechselwirkung mit der Fortentwicklung der epideiktischen Redekunst, zumal des Enkomions; ihr Markenzeichen ist ein feierlicher, dem Thema angemessener Stil. ${ }^{23}$ Freilich handelt es sich um ein Genre, das sich

18 331,20-332,7: Apollons Päane und Hyporchēmata, Dionysos' Dithyramben und Iobakchen, Aphrodites Erōtikoi, schliesslich die an andere Götter gerichteten Hymnen. Zur literarkritischen Analyse vgl. RUSSELL/ WILSON, Menander (s. Anm. 17) $227 \mathrm{f}$.

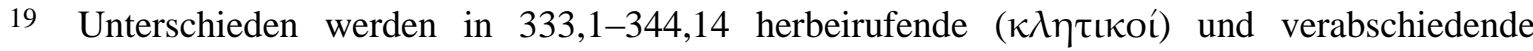
( $\dot{\alpha} \pi \mathrm{\sigma} \pi \varepsilon \mu \pi \tau \iota \kappa o i ́)$, naturphilosopische ( $\phi v \sigma \iota \kappa o i ́)$ und mythische, genealogische und fiktionale,

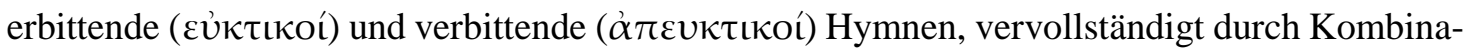
tionen von zweien, dreien oder rundweg allen.

20 Jos., ant 7,305 (David); 2,346; 4,303 (Mose); cf. Philon, Mos 1,23; contemp 29.80.84; D.R. VANCE, The Question of Meter in biblical Hebrew Poetry, 2001 (SBEC 46), 47-51.

21 W. PEEK, Der Isishymnus von Andros und verwandte Texte, Berlin 1930.

22 Vgl. PGM II 237-266.

23 Zu den „Postulaten der griechischen Kunstprosa“ (Schmuck der Redefiguren; Nähe zur Poesie; Rhythmik) vgl. E. NORDEN, Die antike Kunstprosa, Leipzig ${ }^{3} 1915=$ Darmstadt ${ }^{9} 1983,50-63$; ferner A. DIHLE, Art. Prosarhythmus, DNP 10 (2001) 434-437. 
sichtbar erst im Kontext der zweiten Sophistik, also ab dem späten 1. Jh. n.Chr., entwickelt. ${ }^{24}$

Platons Lobreden auf den Eros zeigen, wie das Enkomion bereits im 4. Jh. v.Chr. auch göttliche Wesen zu seinem Gegenstand macht, hier allerdings ohne direkten Anschluss an die hymnische Tradition. ${ }^{25}$ Zwischen Platon und Aristeides' Reden auf Götter um die Mitte des 2. Jh. n.Chr. lassen sich nur verstreute Spuren von Prosahymnen nachweisen, ${ }^{26}$ v.a. eingebunden in andere literarische Gattungen. ${ }^{27}$ Immerhin bezeugt Quintilian, dass die rhetorische Theorie nunmehr auch das Lob der Götter einbezieht. ${ }^{28}$ Seit dem 1. Jh. v.Chr. finden im Rahmen festlicher Anlässe musische Agone statt, in denen nicht nur metrische, sondern auch prosaische Hymen vorgetragen werden. ${ }^{29}$ Im Rahmen des Götter- und Kaiserkults agierten nach Ausweis einiger kleinasiatischer Inschriften theologoi, denen im Unterschied zu den hymnodoi die Rezitation von Prosahymnen oblag. ${ }^{30}$ Neben der Agonistik wurden Festreden auch vor Rats- und Volksversammlungen und bei öffentlichen Banketten vorgetragen. Gleichwohl thematisiert der Rhetor Aristeides, dem wir immerhin zehn solcher Hymnen verdanken, seine metabasis eis allo genos ausdrücklich als

24 Vgl. dazu neben der klassischen Passage bei NoRDEN, Kunstprosa (s. Anm. 23) 843-846 v.a. L. PERNOT, La rhétorique de l'éloge dans le monde gréco-romain, 1993 (EAug 137/38), 82-84; 216-238; ders., Hymne en vers ou hymne en prose?, in: LEHMANN, Hymne (s. Anm. 17) 169188.

25 Vgl. besonders die Rede Agathons, Platon, symp 194e-197e; zum Schluss wird das Lob dem Gott dargebracht. Vgl. R. VELARDI, Le origini dell' inno in prosa tra V e IV secolo A.C., in: A.C. CASSIO (Hg.), L'inno tra rituale e letteratura nel mondo antico, Rom 1993, 205-231.

26 Die Produktion von Prosahymnen beginnt antiken Referaten zufolge mit dem Herakles-Lob des

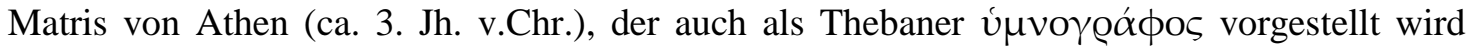
(FGrHist 39 T 1a); vgl. dazu TH.M. BANCHICH, Matris (39), Brill's New Jacoby (online). Ptolemaios Chennos (1. Jh. n.Chr.; bei Photios, bibl 190, 148a/b) listet weitere - uns ganz unbekannte - „Hymnographen“ bzw. städtische Hymnendichter auf.

27 So etwa der Hymnus auf die Philosophie bei Cic., Tusc 5,5. Ein Lob der Erde, allerdings nicht mit deutlicher Textzäsur, bietet Plin., nat hist 2,154. Aufschlussreich ist der Befund bei Ps.Aristot., de mundo, wohl aus dem späten 1. Jh. n.Chr.: Das Schlusskapitel (7) arbeitet mit hymnischen Sprachformen, etwa der Polyonymie Gottes, aber ein eigentlicher Hymnus findet sich m.E. erst im orphischen Zitat (401a28-b7 = OrphFrg 21a).

28 Quint. 3,7:6-9 (de laude, ohne den Terminus hymnus); vorangegangen war bereits Aristot., rhet 1,9: $1366 \mathrm{a} 30$.

29 Vgl. PERnOt, Rhétorique (s. Anm. 24) 47-50; A. HARDIE, Statius and the Silvae, 1983 (ARCA 9), 97-99; GASCÓ, Menander (s. Anm. 17) 3131.

30 Vgl. M. NILSSON, Geschichte der griechischen Religion, II, ${ }^{3} 1974$ (HAW V 2/2), 379-381; E.L. BOWIE, Greek Sophists and Greek Poetry in the Second Sophistic, ANRW II.33.1 (1989) 209258: $213 ; 221$. 
Neuerung. ${ }^{31}$ Noch im 4. Jh. hält es Libanios für bemerkenswert, dass ein Redner einen „Hymnus ohne Metrum“, in seinem Fall auf Artemis, verfasst. ${ }^{32}$ Es ist kein Zufall, dass der einzige erhaltene Prosahymnus aus hellenistischer Zeit, der die Einwirkung epideiktischer Rhetorik erkennen lässt, eine Isis-Aretalogie, also ein Importprodukt, darstellt. ${ }^{33}$

Gerade die spärlichen Überlieferungen legen den Schluss nahe, dass der Prosahymnus bis in die Kaiserzeit ganz im Schatten des metrischen Hymnus steht. Er stellt keineswegs ein etabliertes Genre dar, das der urchristlichen Hymnodik den Weg bereitet hätte. ${ }^{34}$ Erst mit der Literatur des 2. Jh. n.Chr. erschliesst sich der Prosahymnus dasjenige Terrain, das bislang dem metrischen Hymnus vorbehalten war; so findet er sich etwa bei Epiktet, bei Apuleius und später bei Julian. ${ }^{35}$

Die Breitenwirkung der Konjunktur epideiktischer Rede seit dem 2. Jh. zeigt sich daran, dass Menander den Prosahymnus gleichberechtigt neben den gedichteten stellt und ihn sogar privilegiert. Der Rhetoriklehrer unterstreicht, dass für Prosa strengere Stilregeln gelten als für Poesie. ${ }^{36}$ Dem modernen Leser fällt dabei auf, dass es sich bei nicht wenigen Beispielen, die aus nichtpoetischen Klassikern stammen (vorzüglich aus Platon, sodann aus Thukydides und Isokrates), überhaupt nicht um Textpassagen handelt, die wir heute als ,hymnisch' oder gar als Hymnus charakterisieren würden - wieder ein Indiz für die zuvor festgestellte breite Semantik von úuvos.

Eine didaktische Hilfe für die Wahrnehmung von Kunstprosa bildet die kolometrische Darstellung ( $\kappa \alpha \tau \dot{\alpha} \kappa \tilde{\omega} \lambda \alpha \kappa \alpha \grave{\imath} \kappa o ́ \mu \mu \alpha \tau \alpha$ ). Im Layout griechischer Textausgaben sollte sie allerdings m.E. äusserst sparsam eingesetzt werden. ${ }^{37}$

Innerhalb des breiten Spektrums epideiktischer Rede lässt sich der Prosahymnus formal nur schwer vom Enkomion (bzw. anderen Typen des

31 Aristeides, or 45,1-14. Zu den Hymnen (or 37-46) vgl. D.A. RuSSELL, Aristides and the Prose Hymn, in: ders. (Hg.), Antonine Literature, 1990, 199-219; J. GOEKEN, Pourquoi furent composés les hymnes an prose d'Aelius Aristide?, in: LehmanN, Hymne (s. Anm. 17) 189-204.

32 Liban., or 5,2. - Noch im 5. Jh. bezeugt Marinos, vit Procl 1,15-17 S./S. für den paganen Kult Hymnen mit und ohne Metrum.

33 Y. GRANDJEAN, Une nouvelle Arétalogie d'Isis à Maronée, 1975 (EPRO 49); PERNOT, Rhétorique (s. Anm. 24) 47; 220.

34 Anders KrentZ, Epideiktik (s. Anm. 17) 71-84; A. YARBro Collins, Psalms, Philippians 2:611, and the Origins of Christology, Bibl. Interpr. 11 (2003) 361-372.

35 Epiktet, diss 1,16:16f; zu Apuleius, met 11,2:1-4 und 11,25:1-6 (ohne Bitte) vgl. S. JACQUES, Le discours d'Isis et la deuxième prière de Lucius dans les Métamorphoses d'Apulée, in: LEHMANN, Hymne (s. Anm. 17) 507-520. - Julians Preisreden auf Helios (or 4) und auf die Göttermutter (or 5) stellen nicht als ganze Hymnen dar, diese finden sich jeweils erst in der Schlusspassage $(4,43 \mathrm{f} ; 5,20)$; anders D. BORRELLI, Sur une possible destination de l'hymne aux dieux chez l'empereur Julien, in: LEHMANN, Hymne (s. Anm. 17) 243-258.

37 Vgl. PEPPARD, Poetry (s. Anm. 6). 
Enkomions) abgrenzen, sieht man von der genannten inhaltlichen Differenzierung im Blick auf das Objekt bzw. den Adressaten ab. Als Signale spezifisch hymnischer Sprache, die auf die Kulttradition sowie auf bestimmte Platonpartien zurückgehen, fungieren kurze Kola, einfache nicht-periodische Strukturen, Asyndeton, Polysyndeton, Anapher und erhabenes Vokabular, zusammen mit Partizipial- und Relativstil. ${ }^{38}$

2. Der griechische Hymnus hat, obschon dies der antik-rhetorischen Beschreibung entgangen ist, einen dreiteiligen Aufbau: Anrufung, Preis und Bitte. ${ }^{39}$ Die Klimax kann im dritten Teil liegen; Anruf und Preis etablieren die für das menschliche Anliegen notwendige Kommunikationsbasis. Das Hauptgewicht kann sich aber auf den Mittelteil verschieben. So ist der dritte Teil optional - er kann fehlen oder er nimmt ganz die Gestalt des Danks an. ${ }^{40}$ Hymnen kommunizieren mit der Gottheit sowohl in der zweiten Person (Du-Stil) wie in der dritten Person (Er-Stil); ${ }^{41}$ lediglich im dritten Teil dominiert die zweite Person. Die Sprechrichtung zum Göttlichen hin gilt auch bei der dritten Person. Der Hymnus organisiert seinen Bauplan unter Rückgriff auf ein reiches Set von Bausteinen. Partizipial- und Relativsätze, typische Merkmale hymnischer Sprache, finden sich im mittleren, prädikativen bzw. argumentativen Teil; er stellt Mythos und Wesen der Gottheit heraus.

3. Von Haus aus haben Hymnen einen kultischen Sitz im Leben. Sieht man aber von einigen Inschriften ab, sind sie uns grösstenteils in literarischer Gestalt überliefert. Hier muss dann nochmals zwischen Hymnen, die mehr oder weniger unmittelbar auf kultische Vollzüge zurückweisen, und literarischen Hymnen, die sich davon ganz emanzipiert haben, unterschieden werden; dabei gibt es zahlreiche Wechselwirkungen. Wie kultisch ist ein hymnisches Gedicht, das an einem Symposion zusammen mit einer Libation rezitiert wird? Wie nah steht der Prooimion-Hymnus an einem rhapsodischen Wettbewerb oder das Chorlied in einer Tragödie dem städtischen, mit Opferhandlungen verbundenen

38 Vgl. z.B. K. KEYsSNER, Gottesvorstellung und Lebensauffassung im griechischen Hymnus, Stuttgart 1932, 22-48; RUSSELL, Aristides (s. Anm. 31) $200 \mathrm{f}$.

39 Die Entdeckung der Dreiteiligkeit geht zurück auf C. AUSFELD, De Graecorum precationibus quaestiones, JCPh.S 28 (1903) 503-547. Zur Typologie vgl. besonders H. MEYER, Hymnische Stilelemente in der frühgriechischen Dichtung, Diss. Köln 1933, 3-8; K.-D. DORSCH, Götterhymnen in den Chorliedern der griechischen Tragiker, Diss. München 1983, 6-12; FURLEY/ BREMER, Hymns (s. Anm. 11) 50-64.

40 Die Bitte tritt in den homerischen Hymnen meist ganz zurück; sie fehlt z.B. auch in Kallim., hymn 2; 3; 4; Mesomedes, hymn 2; 5; Aristeid., or 39; 40; 41; 42; 43 (der Hymnus steht ganz im Zeichen des Danks; ebenso Liban., or 5); Synes., hymn 8; 9. Nach Menander fehlt die Bitte beim naturphilosophischen Hymnus $(337,25 f)$.

41 Die erste Person, der Selbstruhm der Gottheit, findet sich selten in griechischen Hymnen; er ist häufig in denjenigen des Alten Orients (bis zu den Isis-Aretalogien), nicht aber in Israel. - Der manchmal behauptete Gegensatz von „rhapsodischen“ (Er-Stil) und „kultischen“ (Du-Stil) Hymnen wird relativiert von FURLEY/ BREMER, Hymns (s. Anm. 11) 42f. 
Götterkult? Bereits im Bereich antiker Hymnologie stellen sich dem in der Exegese beliebten Kurzschluss von der literarischen direkt auf die kultische Ebene Schwierigkeiten entgegen.

Holzschnittartig gesprochen lassen sich Hymnen funktional differenzieren - sie nehmen kultische, didaktische oder/und ästhetische Funktionen wahr. Im Blick auf literarische Hymnen ist ihre Platzierung und Funktion in grösseren literarischen Gattungen wie Drama, Roman oder Traktat zu beachten. ${ }^{42}$ Deshalb gilt es, die beiden Kommunikationsebenen des Hymnus sorgfältig zu unterscheiden: Einerseits adressiert er die Gottheit, andrerseits interagieren Sänger und Gemeinde bzw. Autor und Leserschaft.

4. Schliesslich ist auf die Attraktivität des Hymnus für die philosophische und theologische Reflexion hinzuweisen, die sich von Kleanthes, vielleicht schon von Empedokles, bis Proklos durchhält. ${ }^{43}$ Das Nachdenken über Gott erreicht geradezu seine höchste Stufe, wenn es sich über die diskursive Reflexion zum hymnischen Lob aufschwingt. ${ }^{44}$ Der philosophische Hymnus verdankt sich einerseits der allegorischen Hermeneutik, andrerseits der Personifikation von Abstracta, etwa der Tugend, der Gesundheit oder der Philosophie. Gerade in letzterem Fall sind Enkomion und Prosahymnus fast nicht mehr unterscheidbar.

\subsection{Hymnen als religionswissenschaftlicher Gegenstand}

1. Hymnen eignen sich für den Kulturvergleich. ${ }^{45}$ Neben charakteristischen Unterschieden zwischen griechischen und orientalischen Hymnen, die Eduard Norden bahnbrechend herausgearbeitet hat ${ }^{46}$ gibt es ein breites Inventar an Formelementen, die sich im mediterranen Raum und weit darüber hinaus kulturübergreifend erheben lassen. Das Feld reicht von Strukturen - wie der Abfolge von Anrufung und Preis - bis zu den Merkmalen hyperbolischer Sprache im Partizipial- und Relativstil.

Für unseren Bereich drängt sich die alttestamentliche Gebetsdichtung auf, an die Hermann Gunkel die Kategorie des Hymnus herangetragen hat. ${ }^{47}$ Mittlerweile hat man Abstand genommen von reinen Urformen oder von festen Gattungsmerkmalen zugunsten der Beschreibung der Einzeltexte, die lediglich durch ein Feld zumeist optionaler Elemente wie Lobaufforderung, Begründungspartikel, Partizipialstil und Sprechrichtung zu Gott in zweiter oder

$42 \mathrm{Zu}$ Hymnen in narrativen Gattungen vgl. G. RISPOLI, La présence de l'hymne dans le roman grec antique, in: LeHMANN, Hymne (s. Anm. 17) 259-273 sowie die Beiträge von M.L. DELBRIDGE und A. ENERMalm in M. KILEY u.a. (Hg.), Prayer from Alexander to Constantine, London 1997, 171-180**.

43 Vgl. M. Meunier, Hymnes philosophiques, Paris 1935; D. FurLeY, Types of Greek Hymns, Eos 81 (1993) 21-41; G. ZUNTZ, Griechische philosophische Hymnen, Tübingen 2005; speziell zu Kleanthes (SVF I 537) vgl. J. THOM, Cleanthes' Hymn to Zeus, 2005 (STAC 33); P.A. MEIJER, Stoic Theology, Eburon 2007, 209-228.

44 Proklos zufolge steht zuoberst der apophatische theologische Hymnus, gerichtet an das Eine, wie ihn der platonische Parmenides repräsentiert (in Parm 6, 1191:34f C.).

45 Vgl. besonders F. STOLZ, Vergleichende Hymnenforschung, in: BURKERT/ STOLZ, Hymnen (s. Anm. 11) 109-119; G. FreYbURGer/ L. Pernot, Préface, in: LeHMANN, Hymne (s. Anm. 17) I (,Païen ou chrétien, rituel ou artistique, en vers ou en prose, sérieux ou parodique, parlé ou chanté, l'hymne est omniprésent dans les mondes antiques").

46 E. NORDEN, Agnostos Theos. Untersuchungen zur Formengeschichte religiöser Rede, Berlin 1913 (= Darmstadt 1974), besonders 220-223; 239.

47 H. GUNKEL, Einleitung in die Psalmen, Göttingen ${ }^{4} 1985$; ferner F. CRÜSEMANN, Studien zur Formgeschichte von Hymnus und Danklied in Israel, 1969 (WMANT 32). 
dritter (!) Person verbunden sind. ${ }^{48}$ Markenzeichen der Hymnen ist ausserdem ihre ,gleichsam magnetische Kraft, theologische Reflexion anzuziehen"; ${ }^{49}$ dies verbindet sie nicht nur mit der griechischen, sondern etwa auch mit der ägyptischen Hymnik. Die Öffnung des formgeschichtlichen Rasters kommt uns im Bereich des frühen Judentums und Christentums insofern entgegen, als sie es erlaubt, ein breites Spektrum von Texten einzubeziehen, freilich mit der Gefahr, in der überwältigenden Erscheinungsfülle Unterscheidungskriterien ganz zu verlieren. Die frühjüdische Literatur enthält eine reiche Zahl von Psalmen, Hymnen und Gebeten, die sich angemessen mit den in der alttestamentlichen Formgeschichte erhobenen Kategorien beschreiben lassen. ${ }^{50}$ Aus griechischer Perspektive handelt es sich bei ihnen so gut wie bei den Liedern des Psalters um Prosahymnen aus dem Schatz barbarischer Frömmigkeit und Weisheit. Ihnen lassen sich die bereits genannten Isisaretalogien zur Seite stellen. ${ }^{51}$

2. Es steht ausser Zweifel, dass das Urchristentum in hohem Ausmass an der Tradition frühjüdischer Gebets- und Hymnendichtung partizipiert, wie überhaupt am reichen Arsenal an Gottesprädikationen, den Bausteinen dieser Redeformen. ${ }^{52}$ Zugleich rezipiert es nicht weniger als das zeitgenössische Judentum die lobpreisenden Sprachformen seiner hellenistischen Umwelt. Man ist gut beraten, gerade in diesem Bereich grundsätzlich von erheblichen kulturellen

48 Vgl. H. SPIECKERMANN, Alttestamentliche „Hymnen“, in: BURKERT/ STOLZ, Hymnen (s. Anm. 11) 97-108; ders., Hymnen im Psalter, in: E. ZENGER (Hg.), Ritual und Poesie, 2003 (HBS 36), 137-161.

49 So SPIECKERMANN, „Hymnen“ (s. Anm. 48) 104; vgl. ders., Hymnen (s. Anm. 48) 140 („Theologiegeneratoren par excellence").

50 Übersichten bieten J.H. CHARLESwORTH, A Prolegomenon to a new Study of the Jewish Background of the Hymns and Prayers in the New Testament, JJS 33 (1982) 265-285; R.D. Chesnutt/ J. Newman, Prayers in the Apocrypha and Pseudepigrapha, in: KILEY, Prayer (s. Anm. 42) 38-42. Zu Qumran vgl. E. CHAZON, Psalms, Hymns and Prayers, EDSS 2 (2000) 710715; A.K. HARKINS, The Community Hymns Classification, DSD 15 (2008) 121-154.

51 Anders PEEK, Isishymnus (s. Anm. 21) 159, der sich nur am griechischen Hymnus orientiert.

52 Vgl. G. DeLling, Geprägte partizipiale Gottesaussagen in der urchristlichen Verkündigung, in: Studien zum Neuen Testament und zum hellenistischen Judentum, Göttingen 1963, 401-416; CH. BÖTTRICH, Die neutestamentliche Rede von Gott im Spiegel der Gottesprädikationen, BThZ 16 (1999) 59-80; ders., „Gott und Retter“. Gottesprädikationen in christologischen Titeln, NZSTh 42 (2000) 217-236. 
Austauschprozessen auszugehen und an den Einzeltexten zu eruieren, welche konkrete Gestalt die formalen und inhaltlichen Elemente hymnischer Sprache annehmen. Spezielle Aufmerksamkeit verdient bei ihrer Formbestimmung die Wahl der Beschreibungssprache. In griechischer Sprache formulierte bzw. übersetzte Psalmen und Lieder alttestamentlich-jüdischen (wie überhaupt orientalischen) Typs sind aufgrund ihres fehlenden quantitierenden Metrums als - gehobene - Prosa anzusprechen, für deren Beschreibung die antike Rhetorik geeignete Instrumente bereitstellt. Umgekehrt spiegelt ihre Sprachgestalt mehr oder weniger stark Struktur und Stil semitischer Poesie, folgt also den Regeln für Vers, Rhythmus und Klang, die die Alttestamentler und Orientalisten mit viel Mühe erheben. ${ }^{53}$ Anstatt die Beschreibungssprachen programmatisch gegeneinander auszuspielen, versucht man besser, sie ergebnisorientiert an den Einzeltexten zu testen und zu ermitteln, ob sie komplementär oder alternativ funktionieren.

3. Wir kehren zurück zur Religionswissenschaft. Ein Punkt bedarf besonderer Klärung, nämlich das Verhältnis des Hymnus zum Gebet. ${ }^{54}$ Von Haus aus gehören beide eng zusammen (das ebenfalls komplexe Verhältnis zur Magie klammern wir aus). Die Abgrenzung ist delikat, da auch das Gebet ähnlich strukturiert sein kann und mit preisenden Elementen arbeitet. ${ }^{55}$ Beiden eignet die Sprechrichtung zum göttlichen Wesen. Zwei Kennzeichen erlauben eine Unterscheidung, nämlich Sprachtyp und Kommunikationstyp. Der Hymnus arbeitet erstens mit einer kunstvollen Diktion - stilistisch, poetisch und metrisch geformt - und ist deshalb auch Gegenstand rhetorischer Analyse geworden. Die Sprache des Gebets ist oft viel schlichter. Zweitens hat der Hymnus in kommunikativer Hinsicht sein Gravitationszentrum im Gotteslob, in der Anbetung. ${ }^{56}$ Er bedarf

53 Vgl. dazu W.G.E. WATSON, Classical Hebrew Poetry, 1984 (JSOT.SS 26); K. SEYBOLD, Poetik der Psalmen, Stuttgart 2003; J.F. HobBINS, Regularities in ancient Hebrew Verse, ZAW 119 (2007) 564-585.

54 Vgl. dazu besonders PULleyn, Prayer (s. Anm. 12) 39-55; ferner F. HeILER, Das Gebet, München ${ }^{3}$ 1921, 157-190; P. WÜLFING, Hymnos und Gebet, Studii Classice 20 (1981) 21-31; FURLEY/ BREMER, Hymns (s. Anm. 11) 3f; LÖHR, Gebet (s. Anm. 7) 437-439.

55 Nicht empfehlenswert ist die Definition des Hymnus als ,sung prayer“ (so J.M. BREMER, Greek Hymns, in: H.S. VERSNEL/ E.T. VAN STRATEN (Hg.), Faith, Hope and Worship, 1981 [SGRR 2], 193-215: 193); vgl. die Selbstkorrektur in FURLEY/ BREMER, Hymns (s. Anm. 11) 3.

56 Eine hübsche Differenzierung zwischen Psalmgebeten und Hymnen nimmt Johannes Chrysostomos in seiner Auslegung von Kol 3,16 vor (hom 9,2 in Col [PG 62, $363=11,453$ M.]): „Die

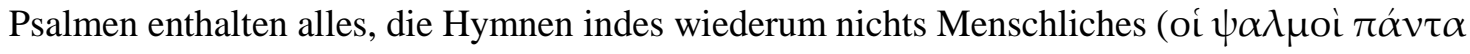

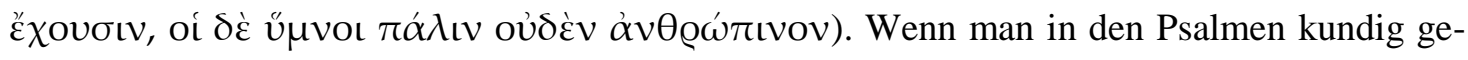

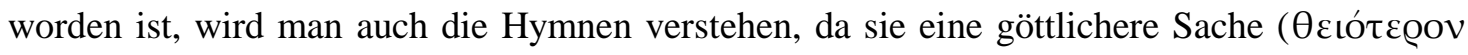

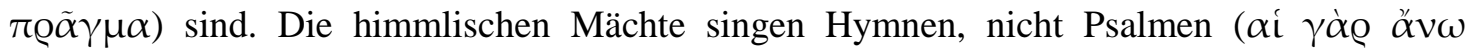

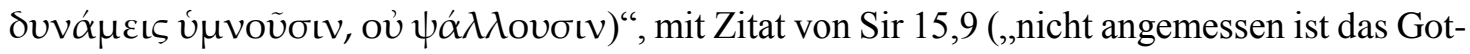

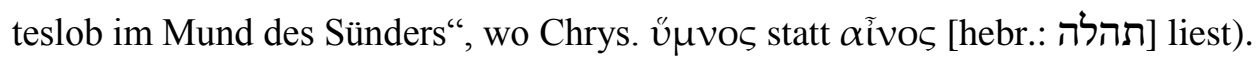


so nicht notwendig einer Gebetsbitte. Die Interaktion mit der Gottheit unterscheidet sich charakteristisch vom Gebet; der Hymnus ehrt die Gottheit mit gehobener, feierlicher Sprache $\left(\tau \iota \eta^{\prime}\right)$. Er stellt selber eine Gabe an die Gottheit dar und kann deshalb auch auf ein Opfer verzichten, das im paganen Raum üblicherweise mit dem Gebet verbunden ist. Die idealtypische Differenzierung von Hymnus und Gebet wird freilich durchkreuzt von ihrer intensiven Wechselwirkung.

4. Die grosse Nähe des Hymnus zum Gebet trotz seines spezifischen Profils bildet einen fundamentalen Eckwert auf unserem langen Weg zu einer Eingrenzung des Phänomens. Der Hymnus hat, kultisch oder literarisch, die Funktion, die Gottheit zu vergegenwärtigen - in griechischen Hymnen gern mit dem Ruf nach ihrem epiphanialen Kommen verbunden. Die Leistung hymnischer Sprache besteht in der Repräsentation der Gottheit. Insofern zählt die Epiklese, die Invokation, ${ }^{57}$ zu den unverzichtbaren Elementen eines Hymnus, bestehe sie auch nur in der schlichten Nennung des Götternamens. Ein Hymnus hat also eine mindestens virtuelle kletische Dimension. Das Moment der Repräsentation bezieht sich sowohl auf seine kultische, seine didaktische wie seine ästhetische Funktion. Das heisst: Auch ein literarischer Hymnus zielt darauf, in seinen Lesern bzw. Hörern eine bestimmte, dem Gegenstand angemessene Einstellung zu erzeugen. Er versetzt sie aus ihrer normalen Welt heraus in einen Raum, der durch die Gegenwart des angerufenen Wesens bestimmt ist. Dies gilt von Sapphos Hymnus auf Aphrodite, die Macht der Liebesgöttin, nicht weniger also von Kleanthes' Lob des Zeus, die alles zum Graden richtende kosmische Intelligenz, oder von Ciceros Anrufung der Philosophie, der weisen Führerin zum Leben. ${ }^{58}$ Natürlich schert an diesem Punkt eine besondere Gattung aus, der parodische Hymnus.

5. So legt sich folgende Sprachregelung nahe: Ein Hymnus besteht in lobendem bzw. preisendem Sprechen oder Singen von und $z u$ göttlichen Wesen (Sprechrichtung). Seine Sprechhandlung zielt auf die Repräsentation der Gottheit. Unsere relativ enge Anbindung des Hymnus an das Gebet nimmt mit Absicht eine bedeutsame Weichenstellung vor, die die zu erwartenden Resultate ein gutes Stück weit kanalisiert.

\section{Ein neutestamentlicher Rundgang}

Anders als das Alte Testament oder als griechische Sammlungen enthält das Neue Testament keine Dichtungen oder Reden, bei denen es sich als ganze um „Hymnen“ oder „Gebete“ handelt. Wir haben es vielmehr mit anderen literarischen Gattungen zu tun, die allenfalls Hymnen enthalten. Eine grundlegende methodische Entscheidung besteht darin, primär auf der Ebene der vorfindlichen Texte danach zu fragen, ob ein Hymnus vorliegt oder nicht.

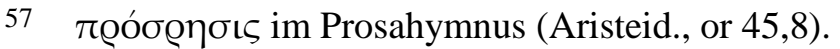

58 Sappho, frg 191 L./P.; Kleanthes, SVF I 537; Cic., Tusc 5,5. 
Davon zu unterscheiden ist die Frage, ob unsere Texte allenfalls Gebrauch von Hymnen machen, die sich in ihrer schriftlichen oder geprägten mündlichen Gestalt rekonstruieren lassen. Und noch einmal ist davon die Frage abzusetzen, ob diese postulierten Hymnen ursprünglich eine kultische Funktion hatten.

Bewegen wir uns auf der Ebene der vorfindlichen Texte und arbeiten mit der oben vorgeschlagenen Sprachregelung, dann können wir nur dort einen Hymnus erwarten, wo der Makrotext selber Signale bietet, die seiner kletischen Dimension Raum geben. Der Leser wird ein Stück weit aus dem Erzähl- oder Argumentationszusammenhang hinausversetzt und in die Bewegung des Hymnus, die auf die Repräsentation des göttlichen Wesens zielt, hineingenommen. Es bedarf dafür nicht notwendig einer Epiklese, auch ein Ausruf, eine Zitationsformel oder eine anderweitige Zäsur auf der Textoberfläche, die den Übergang zum Hymnus indiziert, ist ausreichend. ${ }^{59}$

Aus ökonomischen Gründen stellt die folgende Durchmusterung repräsentative Texte zusammen, ohne Vollständigkeit zu beanspruchen. Dabei stellen sich Fragen der Abgrenzung zu anderen liturgisch geprägten Formen, etwa zu Eulogie oder Doxologie, die aber im Unterschied zu den Hymnen eine v.a. biblisch-jüdische Sonderbildung darstellen. ${ }^{60}$ Besonders schwierig ist die Differenzierung gegenüber Homologie und Bekenntnisformeln, da wir mit vielfachen Wechselwirkungen zu rechnen haben. ${ }^{61}$ Ich orientiere mich in schlichter bibelkundlicher Weise an der kanonischen Folge der Schriften und erlaube mir lediglich aus didaktischen Gründen, den Johannesprolog für den Schluss der tour d'horizon aufzusparen.

1. Das Lukasevangelium bietet uns mit seinen zwei Liedern, die in den Schatz christlicher Hymnodik eingegangen sind, mit dem Magnificat (Lk 1,46-55) und dem Benedictus $(1,68-$ 79), ,Psalmen', die ganz in alttestamentlicher Tradition stehen. Sie lassen sich unschwer als Hymnen, verbunden mit Elementen des Danklieds des Einzelnen, identifizieren; ${ }^{62}$ beide bieten die von uns gewünschte

59 Dieses Kriterium wurde oben auch der Analyse einiger griechischer Prosahymnen zugrunde gelegt (bei Anm. 27; 35).

60 Eulogien: Röm 1,25; 9,5; 2Kor 11,31; auch Lk 1,68; am Briefeingang 2Kor 1,3f; Eph 1,3-14;

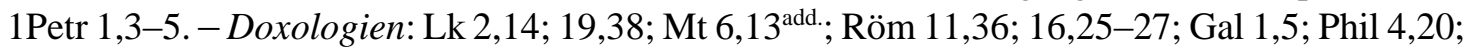
Eph 3,21; 1Tim 1,17; 6,16; 2 Tim 4,18; Hebr 13,2; 1Petr 4,11; 5,11; Jud 24f; 2Petr 3,18; Apk 1,6; 5,13f; 7,10.12; 19,1; Did 8,2; 9,2-4. Vgl. G. WAINWRIGHT, Doxology, London 1980, 182 217.

61 Zur Differenzierung vgl. W. GLOER, Homologies and Hymns in the New Testament, PRSt 11 (1984) 115-132.

62 Zur Analyse, die in Bezug auf die Gattungsfrage weitgehend einmütig ausfällt, vgl. T. KAUT, Befreier und befreites Volk, 1990 (BBB 77); U. MITTMANN-RICHERT, Magnifikat und Benediktus, 1996 (WUNT II/90); R.J. DILLON, The Benedictus in Micro- and Macrocontext, CBQ 68 (2006) 457-480; M. WOLTER, Das Lukasevangelium, 2008 (HNT 5), 99f; 110-112; TH.P. OSBORNE/ N. SIFFER, Les ,hymnes“ du récit de l'enfance de l'évangile de Luc, in: GERBER/ KEITH, Hymnes (s. Anm. 6) 281-308. 
Textabgrenzung durch den Übergang in direkte Rede (V. 46a. 67b). Beim Magnificat, einem hochorganisierten Patchwork biblischer Sprache, führt das zweifache begründende ǒ $\tau$ (V. 48a.49a) von der Einleitung zum Hauptteil, der das Heilshandeln Gottes in dritter Person mit Prädikationen und mehrfachem Parallelismus membrorum preist. Der Hymnus, in dem Gott fast durchwegs als Subjekt agiert, respondiert auf die Engelankündigung von der Geburt des Messias, ist also kontextuell sinnvoll platziert. Auch das mit einer Eulogie eingeleitete $\mathrm{Be}$ nedictus arrangiert biblische Phrasen, allerdings in komplexerem Satzbau; Gottesprädikationen dominieren nur den ersten Teil (V. 68-75). In seinem Kontext verschränkt es Johannesgeburt und Jesusgeburt. Beide Hymnen stehen genau an dem Ort, wo Israels Verheissungsgeschichte in seine Erfüllungsgeschichte übergeht. Für beide reklamiert eine überwältigende Mehrheit der Exegeten vorlukanische Herkunft, im Fall des Benedictus gern unter Ausschluss redaktioneller Verse oder Versteile. Wie erfolgreich wäre ein erneuter Versuch, die beiden Hymnen als Dichtungen des Auctor ad Theophilum zu beschreiben? Man müsste zeigen können, dass sich das Sondervokabular der Psalmen-Mimesis des mit der Septuaginta so vertrauten Lukas verdankt.

Umgekehrt zeigt gerade ein Gebet wie Apg 4,24-30, wie sehr Lk auch mit älterem Material arbeitet. Es handelt sich zwar nicht im Ganzen um einen Hymnus, ${ }^{63}$ da sich das Lob nach der Anrufung lediglich auf V. 24-25a erstreckt. Es macht einem Psalmzitat mit Auslegung Platz, um dann erst in V. 28 wieder kurz aufgenommen zu werden. Anrufung (V. 29) und Bitten (V. 30) bilden den Schlussteil.

2. In Röm 11,33-36 findet sich ein Lobpreis, der nicht nur Paulus' Ausführung über Gottes Gerechtigkeit und Israel beschliesst (Kap. 9-11), sondern überhaupt den ersten Teil des Briefs. Wir haben einen Gotteshymnus vor uns, bei dem die Anrufung bruchlos in den Preis übergeht und in einer Doxologie gipfelt. ${ }^{64}$ Die Dreizahl strukturiert das Ganze in mehrfacher Hinsicht. Bemerkenswert ist die Mischung von hellenistischen und biblisch-jüdischen Elementen; am meisten sticht das erstere bei der Präpositionenreihe in V. 36a sowie bei der Interjektion hervor, das zweite bei der Doxologie (V. 36b), den Schriftzitaten (V. 34f) und den Parallelismen membrorum (V. 33b.34f). Es spricht viel dafür, dass Paulus das Gotteslob eigens für den Abschluss des Briefteils verfasst hat; die Bezüge zumal zu Kap. 9-11 und hier insbesondere zu 11,25-32 sind überaus dicht. Es gibt kaum überzeugende Gründe, einen vorgegebenen hellenistisch-jüdischen Hymnus, den Paulus mit den Schriftzitaten anreichert, $\mathrm{zu}$

63 So Berger, Gattungen (s. Anm. 9) 1151; ders., Formgeschichte (s. Anm. 9) 239.

64 Vgl. dazu besonders G. BoRnKamM, Der Lobpreis Gottes, in: ders., Das Ende des Gesetzes. Paulusstudien, ${ }^{5} 1966$ (BEvTh 16), 70-75. 
postulieren. ${ }^{65}$ Auffällig ist die strikt durchgehaltene theozentrische Perspektive ohne jede Referenz auf Jesus Christus, gerade auch im Vergleich der Präpositionenreihe von V. 36 mit 1 Kor 8,6. Sie ist nicht nur dem Gespräch mit Israel, das Paulus in Röm 9-11 führt, geschuldet (vgl. 9,5), sondern markiert auch eine fundamentale Achse in der Architektur seiner Theologie. ${ }^{66}$

3. Bei Phil 2,6-11 haben wir einen prominenten Repräsentanten der hypothetischen urchristlichen Hymnen vor uns, in den Worten seines Entdeckers, Ernst Lohmeyer: „ein Stück urchristlicher Psalmdichtung“".67 Je nach Wahl der Beschreibungssprache lassen sich vielfältige Kunstmittel benennen, die die Passage aus ihrem Kontext, der seinerseits auch schon artifizielle Formgebung aufweist $(2,1-4)$, herausheben. Es stechen hervor der antithetische und synonyme Parallelismus membrorum, chiastische Strukturen, progressives Enjambement und Anadiplosis. Sie signalisieren den erheblichen Einfluss alttestamentlich-jüdischer Psalmensprache. Wendet man sich der Gesamtstruktur zu, gibt es für die Anordnung der einzelnen Kola zwar viel Spielraum, die Zweiteilung der Passage sticht aber markant heraus. Syntaktisch handelt es sich um zwei relativ komplex gebaute Perioden. Statt von einem Gedicht mit „Strophen“ spricht man besser von kunstvoller Prosa. ${ }^{68}$

65 So wieder R. JEWETT, Romans, 2007 (Hermeneia), 713f.

66 Vgl. J.D.G. DunN, The Theology of Paul the Apostle, Edinburgh 1998, 28-33.

67 E. LOHMEYER, Kyrios Jesus. Eine Untersuchung zu Phil. 2,5-11, SHAW.PH 1927/28.4, Darmstadt $21961,7$.

68 Mit BRUCKER, Christushymnen (s. Anm. 6) $306 f$. 
Handelt es sich um einen Hymnus? Legen wir unsere Sprachregelung zugrunde, so haben wir zwar eine in feierlicher Sprache gehaltene Erzählung vom Handeln und Ergehen eines göttlichen Wesens vor uns - gleichsam einen Mythos -, es fehlt aber der kletische Aspekt. V. 6-8 bilden einen Relativsatz, der seinerseits abhängig ist von einem elliptischen Relativsatz (V. 5b). Es gibt kein Textgliederungssignal, das zu der für den Hymnus typischen Sprechrichtung zum göttlichen Wesen hin überleitet. Anders stellt sich die Sachlage dar, wenn man hinter dem vorfindlichen Textzusammenhang einen Hymnus postuliert, auf dessen invokativen Anfang der Briefautor verzichtet hätte (um allenfalls noch Interpolationen hinzuzufügen). In diesem Fall bieten sich noch einmal Alternativen an: paulinisch oder vorpaulinisch, didaktisch oder/und kultisch. Die m.E. sparsamste Hypothese geht davon aus, dass Paulus, ein hervorragender Stilist, den Text selber verfasst hat, wenn auch nicht unbedingt eigens für sein Schreiben an die Philipper. Sprachliche Argumente für vorpaulinische Herkunft unterschätzen die Modulationskapazität epideiktischer Sprache, inhaltliche Argumente unterschätzen die Kontextverbundenheit des Stücks, auch seines zweiten Teils.

Handelt es sich nicht um einen Hymnus, um was dann? Konjunktur hat unter Berufung auf die Rhetorik das Enkomion. ${ }^{69}$ Der Nachteil dieser Beschreibung besteht darin, dass die Bezüge zum Hymnus in der gesamten Bandbreite seiner Phänomene auf einen Schlag gekappt werden. Mit der Bezeichnung Enkomion platziert man Phil 2 in einem Genre hellenistischer Rhetorik, das zwar in Wechselwirkung mit dem Hymnus steht, aber seinen Schwerpunkt an einem anderen Ort ausgebildet hat. ${ }^{70}$ Mehr noch: Legt man konsequent die Beschreibungssprache der rhetorischen Theoretiker zugrunde, handelt es sich bei einem Enkomion auf ein göttliches Wesen, das von seiner Haltung, seinen Taten und seinem Geschick (samt seiner Interaktion mit einem anderen göttlichen Wesen) berichtet, just um einen Hymnus! Das Fehlen der Epiklese oder der Bitte spielt hier keine Rolle, da die antike Beschreibung des Hymnus seine strukturelle Dreiteilung nicht kennt. ${ }^{71}$ Klassifiziert man also Phil 2 dezidiert als Enkomion im Kontrast zum Hymnus, kombiniert man zwei verschiedene Beschreibungssprachen - eine antike und eine moderne -, ohne dies eigens auszuweisen.

Ich schlage eine Formbestimmung in einer Beschreibungssprache vor, die die Bezüge sowohl zur rhetorischen Typologie wie zur alttestamentlichen Metasprache offen hält: ein hymnisches Christuslob. Unser Text bietet alles, was man von einem Hymnus erwarten darf, unter Einschluss äusserst verdichteter theologischer Reflexion - ausser dem einen: die direkte Sprechrichtung zu Jesus Christus. In seinem Kontext stellt er eine Digression dar, die den Philippern ein verheissungsvolles exemplum christlicher Selbsterniedrigung präsentiert. Das Christuslob hat im Briefganzen, wenn man von einem einheitlichen Dokument ausgeht, eine zentrale Position; es rückt die Lebensform, die im Raum des Christus massgeblich ist $(2,5)$, plastisch vor Augen. Weil die einzig legitime Herrschaft im Himmel und auf Erden

69 Berger, Gattungen (s. Anm. 9) 1178-1189; J. ReumAnN, Philippians, 2008 (AnchB 33B), 339; 364-366.

70 Auch der Vorschlag, wir hätten einen Epainos vor uns (BRUCKER, Christushymnen [s. Anm. 6] 319), leidet unter dieser Verkürzung. Zudem bildet die (auf Aristoteles zurückgehende) Differenzierung zwischen Enkomion und Epainos eine - keineswegs konsistent gehandhabte - Sonderlehre innerhalb der rhetorischen Theoriebildung; vgl. dazu PERNOT, Rhétorique (s. Anm. 24) $118-123$.

71 S. oben bei Anm. 39. 
dem Christus gebührt, ruft es dazu auf, dieser Herrschaft auch im solidarischen Gemeinschaftsleben zu entsprechen. ${ }^{72}$

4. Mit Kol 1,15-20 haben wir einen weiteren Text vor uns, der alle Kriterien hymnischer Rede erfüllt, wiederum abgesehen von der kletischen Dimension. Sein „Entdecker“ ist, von einigen Vorgängern abgesehen, nicht zufällig Eduard Norden, der Vater der neueren Hymnologie. ${ }^{73}$ Die Struktur der Passage ist deutlich zweigeteilt, die Korrespondenzen zwischen beiden Partien sind überaus dicht. Wiederum handelt es sich um einen Prosatext mit zahlreichen Kennzeichen hymnischer Sprache - rückverweisende Pronomina, Partizipialstil, polysyndetisches $\kappa \alpha$ í, kurze Kola, universale Prädikationen u.a. Syntaktisch ist das Ganze Teil eines monströs langen Satzes, dessen Anfang man letztlich in V. 9 zu suchen hat. Die Textstrukturierung im Einzelnen führt zu keinen konsensfähigen Ergebnissen - verkompliziert durch Interpolationshypothesen -; deutlich ist nur, dass die beiden Partien abgesehen von ihrem jeweiligen Anfang überhaupt nicht symmetrisch gebaut sind. ${ }^{74}$ Die Nötigung, ein älteres Überlieferungsstück zu postulieren, hält sich m.E. wieder in Grenzen, ganz abgesehen davon, dass dessen Rekonstruktion methodisch fast nicht mehr kontrollierbar ist. Hinsichtlich der inhaltlichen Spannungen zwischen dem hymnischen Teil und der Argumentation im Briefkontext, v.a. in 2,9-15, dürfte sich eine hermeneutische anstelle einer literarkritischen Erklärung als methodisch weniger aufwendig erweisen. ${ }^{75}$ Das Sondervokabular wiederum lässt sich auch mit der Wahl des Stilniveaus erklären, also rhetorisch statt überlieferungsgeschichtlich.

Für die Klassifizierung bietet sich wie bei Phil 2 das „hymnische Christuslob“ an. Gegenüber dem „Enkomion“76 bietet diese Nomenklatur erneut den Vorzug, dass sie einerseits die hymnische Sprachgestalt und die traditionell mit dem Hymnus verbundene Thematik festhält insbesondere die ausserordentliche Nähe zum philosophischen Hymnus ${ }^{77}-$, andrerseits den Anschluss an die alttestamentlich-jüdische Dichtung, zumal an das Weisheitslob, sicherstellt. Das Christuslob hat in der Argumentation eine entscheidende Funktion: Gegenüber

72 Vgl. S. VolLENwEIDER, Politische Theologie im Philipperbrief?, in: D. Sänger / U. Mell (Hg.), Paulus und Johannes, 2006 (WUNT 198), 457-469.

73 NORDEN, Theos (s. Anm. 46) 250-254; 261.

74 Das je verschiedene, subjektiv anmutende Textlayout in den beiden Auflagen von NESTLE/ALAND ${ }^{26 / 27}$ demonstriert augenfällig den Widersinn kolometrischer Gliederung in einer Textausgabe.

75 Vgl. dazu S. VollenweIDER, „Der Erstgeborene vor aller Schöpfung“ (Kol 1,15-20), in: J. HÜBNER u.a. (Hg.), Theologie und Kosmologie, 2004 (Religion und Aufklärung 11), 61-80. Die Hypothese von Interpolationen innerhalb des Textbestands V. 15-20 (v.a. Kreuzesblut V. 20b oder Engelklassen V. 16c/d) drängt sich nicht wirklich auf. Für die Explikation des „Leibes“ durch „die Kirche“ in V. 18a bietet sich die Alternative einer betont protologischen Deutung der Kirche an; der Verfasser spielt mit den kosmischen Assoziationen des Leibes, ohne aber den Kosmos mit dem Leib zu identifizieren.

76 So BERGER, Formgeschichte (s. Anm. 9) 345; 372; M. Wolter, Der Brief an die Kolosser, 1993 (ÖTBK 12), 71f; U. LuZ, Der Brief an die Kolosser, 1998 (NTD ${ }^{18} 8 / 1$ ) 201. Demgegenüber halten an der Kategorie des Hymnus fest V.A. PIZZUTO, A cosmic Leap of Faith. An authorial, structural, and theological Investigation of the cosmic Christology in Col. 1:15-20, 2006 (CBET 41) 103-111; M.E. GORDLEY, The Colossian Hymn in Context, 2007 (WUNT II/228), 170-203; J. SÁNCHEZ BOSCH, Der Hymnus Kol 1,15-20 in seinem früheren und seinem späteren Kontext, in: P. MÜLlER (Hg.), Kolosser-Studien, 2009 (BThS 103), 23-32; A. DETTWILER, Démystification céleste. La fonction argumentative de l'hymne au Christ (Col 1,15-20) dans la lettre aux Colossiens, in: GERBER/ KeITH, Hymnes (s. Anm. 62) 325-340.

$77 \mathrm{Zu}$ Recht herausgestellt von GORDLEY, Hymn (s. Anm. 76) 229f. 
der Attraktivität der kosmischen Mächte, auf die sich offenbar die kolossische ,Philosophie' berufen hat, stellt es die alles durchdringende Wirklichkeit und Herrschaft Christi, des Schöpfungsmittlers, heraus.

5. 1Tim 3,16 gilt mit Blick auf Struktur und Gleichklang der Zeilen als besonders klares Exempel hymnischer Dichtung, ${ }^{78}$ obschon auf der Ebene des vorfindlichen Textbestands kein entsprechendes kletisches Signal erkennbar ist. Tatsächlich legt sich in diesem Fall die Hypothese der Übernahme eines vorgegebenen Stücks durch den Briefverfasser nahe - da-

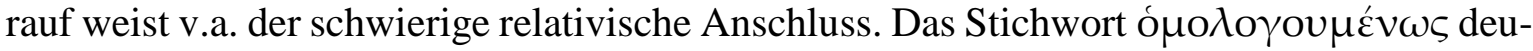
tet freilich eher auf eine kunstvoll gestaltete Bekenntnisformel als auf einen Hymnus, so sehr die beiden Gattungen Lobpreis und Homologie in Wechselwirkung stehen (vgl. 1Kor 8,6). Fast undenkbar für einen Hymnus ist die durchgehende Passivform der Verben, weil dieser geradezu davon lebt, seinen Gegenstand und Adressaten als Subjekt zu würdigen. Wiederum markiert die christologische Partie eine zentrale Position im Briefganzen, wird doch die Kirche als Haus Gottes, das sich am abwesenden Paulus zu orientieren hat, christologisch im „Geheimnis der Frömmigkeit“" verankert (V. 14-16a).

6. Der Verfasser der Apokalypse hat gegen zwanzig in liturgischer Sprache gestaltete Passagen verfasst, die in ihrem jeweiligen Kontext die irdischen Ereignisse aus himmlischer Perspektive deuten. Obschon sie alle mit hymnischen Formelementen arbeiten, sind nur 19,5.6-8 und 15,3f, ein Patchwork der Psalmensprache, als Gotteshymnen alttestamentlichen Typs anzusprechen, ${ }^{79}$ während die übrigen mit anderen Formen wie Akklamation und Doxologie in Wechselwirkung stehen. Wir notieren am Rand, dass Christus als Empfänger zweier „Würdig“-Akklamationen (5,9f.12) und, zusammen mit Gott, zweier Doxologien $(5,13 ; 7,10)$ fungiert. Der Hymnus von Kap. 19 stellt den Höhepunkt der himmlischen Gesänge dar, weil er unmittelbar die Wiederkunft Christi präludiert: Das hymnisch provozierte Kommen des Herrn überwindet die sphärische Dualität von Himmel und Erde, auf der das szenische Arrangement von Kap. 4-19 beruht.

78 Z.B. G.W. KNIGHT, The Pastoral Epistles, 1992 (NIGTC), 182f (creed or hymn); W.D. MounCE, Pastoral Epistles, 2000 (WBC 46), 215f; J. HERZER, „Das Geheimnis der Frömmigkeit“ (1Tim 3,16), ThQ 187 (2007) 309-329.

79 BERGER, Formgeschichte (s. Anm. 6) 242 (mit Verweis auch auf das parodische Element 13,4). Demgegenüber verweist man zumeist summarisch auf „Hymnen“, z.B. H.-P. JÖRNS, Das hymnische Evangelium, 1971 (StNT 5); D.E. AuNE, Revelation 1-5, 1997 (WBC 52A), 314-317; G. SCHIMANOWSKI, Die himmlische Liturgie in der Apokalypse des Johannes, 2002 (WUNT II/154), 32f; 159f; 281f; ders., „Connecting Heaven and Earth“: The Function of the Hymns in Revelation 4-5, in: R.S. BOUSTAN/ A.Y. REED (Hg.), Heavenly Realms and earthly Realities in late antique Religions, Cambridge 2004, 67-84; F. TóTH, Der himmlische Kult, 2006 (ABG 22), 202-211; 450-455; M. MORGEN, Comment louer Dieu, „Celui qui siège sur le trône, ,et l'Agneau'“?, in: GERBER/ KeITH, Hymnes (s. Anm. 62) 209-237. 
7. Den Johannesprolog (Joh 1,1-18) können wir an dieser Stelle nicht einmal ansatzweise würdigen. Angesichts der Unsicherheit, ob es sich bei Texten dieser Art um Kunstprosa oder um Dichtung handelt, stellt sich erneut die Frage nach der angemessenen Beschreibungssprache. Joh 1 zeichnet sich jedenfalls durch eine schlichte, aber vom Erhabenen (ư $\psi \circ \varsigma$ ) bestimmte Diktion aus, an bestimmten Stellen unterbrochen durch Sätze mit gewöhnlicherem Erzählstil, die auf das narrativ angelegte Evangelium vorausweisen (V. 6-8.15). Die Stellung am Anfang des Evangeliums weist die Passage als Proömium aus, ${ }^{80}$ das von Haus aus eigentlich einen eröffnenden Hymnus bildet. Zahlreiche Dichtungen setzen mit einem Hymnus ein; bei Prosawerken gibt es m.W. zwar keine eröffnenden Hymnen, wohl aber Epiklesen, die Gott um Beistand anrufen. Am nächsten steht Joh 1 das Buch Sirach, das mit einem Weisheitshymnus einsetzt. Wir dürfen beim Johannesprolog von einem Logoshymnus sprechen, der den Namen Jesu erst am Schluss nennt (V. 17). Es ist wenig wahrscheinlich, dass der Hymnus unabhängig von der Evangelienlesung und damit ohne Zusätze je kultisch verwendet worden ist; bei den Weisheitshymnen in Sir und Sap ist gottesdienstlicher Gebrauch gewiss nicht der Fall. Der hymnische Prolog hat die Aufgabe, die mythischen Dimensionen der irdischen Jesusgeschichte, die das Evangelium erzählen wird, auszuspannen.

$* * *$

Unser exegetischer Durchgang versuchte, formgeschichtlich zwischen Hymnus im engeren Sinn und hymnischem Lob zu differenzieren. Wir stehen nun vor einem eigentümlichen $E r-$ gebnis: Das Neue Testament dokumentiert einige Gotteshymnen, aber nahezu keine Christushymnen. Dieser Befund steht quer zur klassischen Untersuchung von Reinhard Deichgräber, wonach der im Urchristentum seltene „Gotteshymnus weitgehend vom Christushymnus verdrängt worden ist" ${ }^{\prime 81}$ Zugleich hat sich aber auch gezeigt, dass die urchristlichen Texte auf eine Fülle von hymnischen Sprachmitteln aus ihrer Umwelt zurückgreifen, um Christus als gottgleiches Wesen zu preisen, und diese hymnischen Figuren stehen in ihrem Kontext oft an zentraler Stelle. Lässt sich dieser spannungsvolle Befund erklären?

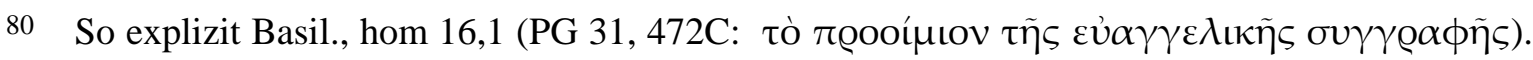
- Zur lektüreleitenden Funktion des literarischen Prologs vgl. M. THEOBALD, Die Fleischwerdung des Logos, 1988 (NTA.NF 20), 267-271; J. ZuMSTEIN, Der Prolog, Schwelle zum vierten Evangelium, in: Ders., Kreative Erinnerung, ${ }^{2} 2004$ (AThANT 84), 105-126; H. WEDER, Ursprung im Unvordenklichen. Eine theologische Auslegung des Johannesprologs, 2008 (BThSt 70), 144-148.

81 DEICHGRÄBER, Gotteshymnus (s. Anm. 2) 60; 106. Er übergeht dabei die Cantica von Lk 1, „weil es sich um ursprünglich jüdische Hymnen handelt" (21; 118 A. 3) - eine in methodischer Hinsicht prekäre Vorentscheidung! 


\section{Monotheismus und hymnisches Christuslob}

Wir sind ausgegangen von der geradezu romantischen Vermutung, dass der grösste Teil einer einst reichen frühchristlichen Hymnodik untergegangen sei. Betroffen wären davon insbesondere die Christushymnen. Die Hypothese hat am Neuen Testament selber kaum Anhalt. Nun bietet auch die patristische Literatur der ersten drei Jahrhunderte auffällig wenige Preislieder auf Christus, und diese sind ihrerseits nicht zufällig in quantitierendem Metrum gehalten und haben meist rein literarische Funktion. ${ }^{82}$ Mehr hymnisches Material enthalten gnostische bzw. gnosisnahe Texte und die christlichen Apokryphen; die Zahl der Christushymnen hält sich allerdings, sieht man von den in vielfacher Hinsicht singulären Oden Salomos ab, in recht engen Grenzen. ${ }^{83}$ Kol 3,16 und Eph 5,19 belegen zwar einen inspirierten gemeindlichen Liedergesang, kaum aber spezifische Christushymnen. ${ }^{84}$ Offen lassen wir die Frage, wie stark man den bekannten Hinweis von Plinius auf Lieder "für den Gott Christus“ belasten kann. ${ }^{85}$ Im Ganzen legt der Befund nicht die Hypothese eines Verdrängungsprozesses nahe, sondern muss als einigermassen repräsentativ ernst genommen werden.

82 So Clemens, paed 3,101:3; Method., symp 284-292; PapOxy 1786 (mit Notenzeichen! C.H. Cosgrove, The earliest Christian Hymn with musical Notation, EL 120 [2006] 257-276); Weiteres bei Th. WOLBERGS, Griechische religiöse Gedichte der ersten nachchristlichen Jahrhunderte, I, 1971 (BKP 40); W. CHRIST/ M. PARANIKAS, Anthologia graeca carminum christianorum, Leipzig $1871=$ Hildesheim 1963, darunter das schwer datierbare Abendlied $\phi \tilde{\omega} \varsigma$ iða@óv. Vgl. ferner J. DEN BOEFT/ A. HILHORST (Hg.), Early Christian Poetry, 1993 (VC.S 22); J. SzÖVÉRFFY, Latin Hymns, Turnhout 1989. - Mit der Zeit setzt sich die akzentuierende, rhythmische Versform durch; vgl. NORDEN, Kunstprosa (s. Anm. 23) 841-867; A. DIHLE, Die griechische und lateinische Literatur der Kaiserzeit, München 1989, 391f; 581-590.

83 Von besonderem Interesse sind Sib 6, ActThom 72.80 und der ,Tanzhymnus' ActJoh 94-96, in dem Christus in erster Person spricht. Zusammenstellung des Materials bei LATTKE, Hymnus (s. Anm. 11) 243-267.

84 Im Gefolge von 1Kor 14,15.26 beziehen sich Kol 3,16 und Eph 5,19 auf geistgewirkte „Psalmen, Hymnen und Oden"; während diese in Kol Gott gelten, sind sie in Eph an den Herrn, d.h. an Christus, gerichtet. Auch im letzteren Fall weist die Formulierung nicht notwendig auf direkt und exklusiv an Christus adressierte Hymnen, zumal es sich um eine geprägte biblische Wendung handelt.

85 Laut Plinius (ep 10,96:7) singen Christen „Christus als Gott einen Wechselgesang“ (so nach der wahrscheinlichsten Deutung: carmenque Christo quasi deo dicere). Das Statement des paganen Beobachters kann auch an Christus adressierte Homologien bzw. Doxologien sowie Gebete in dessen Namen meinen. Zur Diskussion vgl. J.C. SALZMANN, Lehren und Ermahnen, 1994 (WUNT II/59), 133-148. - An vereinzelten späteren Zeugnissen ist zu nennen ein Auszug aus einer antihäretischen Schrift bei Eus., hist 5,28:5, der summarisch auf viele „Psalmen und Oden“ verweist, mit denen Brüder ,von Anfang an das Wort Gottes, Christus, theologisch gepriesen hätten“. Dem steht ebd. 7,30:10 die Nachricht über Paulus von Samosata, den Lehrer des psilos anthropos, entgegen, er habe ,die Psalmen auf unseren Herrn Jesus Christus verboten, weil sie zu neu und erst von neueren Dichtern (!) verfasst worden wären“. 
Der Hauptempfänger von Hymnen bleibt auch im frühen Christentum Gott selber, nicht sein menschgewordener Sohn. Ja, die hymnischen Passagen, die Christi Würde preisen, spiegeln vielfach die Ehre der Gottheit zurück - so in Phil 2,9-11 und in 1Tim 3,16.86 Die hier zu beobachtende Theozentrik pflegen wir mit der Kategorie des christologischen Monotheismus zu beschreiben.

An dieser Stelle lohnt sich ein Seitenblick auf die frühchristlichen Gebete, zumal wir ja Hymnus und Gebet einander eng zugeordnet hatten. Von der frühchristlichen Literatur bis tief ins vierte Jahrhundert zeigt sich ein erstaunliches Phänomen: Die uns erhaltenen gottesdienstlichen Gebete werden nach Ausweis der alten Kirchenordnungen und Liturgien ausschliesslich an Gott adressiert, nicht an Christus, so sehr dieser die im Gebet aktualisierte einzigartige Gottesbeziehung eröffnet und trägt. ${ }^{87}$ Nicht von ungefähr rät Origenes in seiner Abhandlung zum Gebet dazu, Gebete allein an Gott zu richten, nicht an den, der selber betet. 88

Der altkirchliche Befund deckt sich in erheblichem Umfang auch mit der urchristlichen Literatur: Jesus Christus ermöglicht als Mittler und Begründer die Gebetskommunikation mit Gott, wird aber selber nur gelegentlich zum Gebetsempfänger. ${ }^{89}$ Ausnahmen bestätigen die Regel. ${ }^{90}$ Die ab dem Ende des 1. Jh. begegnende Zueignung der Doxologien an Christus allein zeigt aber, dass dieser zunehmend auch als liturgischer Adressat in den Vordergrund rückt. ${ }^{91}$

Unser Bild der um den Christuskult organisierten urchristlichen Gemeinden ${ }^{92}$ bedarf offenkundig der Verfeinerung. Möglicherweise ist es nicht primär der Kult im engeren Sinn, der als ,Brutkammer der hohen Christologie' anzusprechen ist. Gerade in Lob und Gebet partizipiert die Gemeinde am reichen liturgischen Gut Israels und damit an seiner betont monotheistischen Orientierung, auch dort noch, wo sie selber vom Geist erfüllt Psalmen erschafft. Wenn die Christen Jesus gottgleiche Würde zuschreiben, dann vornehmlich im Modus seiner

86 Von den sechs Passivformen in 1Tim 3,16 sind mindestens drei passiva divina.

87 J.A. JUnGMANN, Die Stellung Christi im liturgischen Gebet, ${ }^{2} 1962$ (LWQF 19/20), XV*; 125 131; vgl. B.E. BowE/ J. CABLEAUX, Post New Testament Christian Prayers, in: KILEY, Prayer (s. Anm. 42) 250-253. Von Bedeutung sind insbesondere die Gebete in ConstApp 7/8, für die oft synagogale Herkunft beansprucht wird; jüngst P.W. VAN DER HORST/ J.H. NEWMAN, Early Jewish Prayers in Greek, 2008 (CEJL).

88 Orig., or 15,1-4. Unbeschadet dessen bezeugt sein Werk auch das Gebet an Christus.

89 Vgl. K.-H. OSTMEYER, Kommunikation mit Gott und Christus. Sprache und Theologie des Gebets im Neuen Testament, 2006 (WUNT 197), 115f; 263f; 309; 369f.

90 2Kor 12,8; Apg 7,59f; Joh 14,14. Dank an Christus: 1Tim 1,12. - Gebet an Gott und Christus 1Thess 3,11(-13); 2Thess 2,16f.

91 An Christus gerichtet: 2Tim 4,18; 2Petr 3,18; Meliton, pasch 10; 65; evtl. Hebr 13,21; 1Petr 4,11; Apk 1,6. Trinitarisch: MartPol 14,3; 22,3; erst die neunizänische Theologie bzw. Liturgie

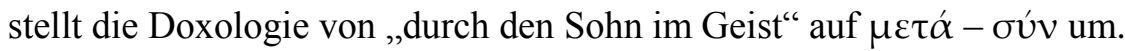

92 Repräsentativ: L.W. HURTADO, Lord Jesus Christ, Grand Rapids 2003; ders., The binitarian Shape of early Christian Worship, in: NEWMAN, Roots (s. Anm. 5) 187-213. 
Teilhabe an Gottes einzigartiger Position - an seinem Namen, seinem Schöpfertum und seiner Weltherrschaft. In anbetenden Sprachgestalten tritt Christus deshalb zugunsten der Gottheit selber in den Hintergrund. Demgegenüber ist eher an Schriftauslegung und Lehrpredigt zu denken, in denen sich die christologische Reflexion in hymnischen Sprachformen ein Stück weit verselbständigt und auf ein Neuland hinauswagt, das Jahrhunderte später die Gestalt der trinitarischen Gottesverehrung und Theologie annehmen wird. 